\title{
Factors affecting seaport capacity
}

\author{
$\underline{\text { S. Islam }}^{\mathrm{a}}$ and T.L. Olsen ${ }^{\mathrm{a}}$ \\ ${ }^{a}$ Department of ISOM, University of Auckland, New Zealand
}

Email:misl086@aucklanduni.ac.nz

\begin{abstract}
One of the most important dynamic problems that decision makers face in today's maritime ports is where and how to upgrade the existing port capacity for rising port demands due to continuous growth in containerized trade and the tendency for bigger ships to visit ports. Academia and corporate interests in capacity planning and capacity management have risen considerably in recent years. To establish the field further, the purposes of this paper are three fold. It (1) identifies consequences of capacity shortage at seaports and corresponding supply chains; (2) offers a conceptual framework to summarize the research in the field concerned with the factors influencing seaport capacity using a holistic approach after reviewing academic and industry-related papers; (3) and finally, concludes by suggesting promising research tracks on factors affecting capacity. In Particular, we explore the specific roles of deterministic simulation and stochastic simulation as future research directions in this rapidly changing and challenging maritime domain. This study is significant as there is limited literature on this subject concerning factors affecting capacity and studies carried out so far on capacity improvement mechanisms are constrained principally by the lack of integrated points of view.
\end{abstract}

Keywords: Simulation, productivity, performance, container terminal, capacity 


\section{INTRODUCTION}

Shipping is the cheapest method of all other common competing modes of transportation. Shipping carries a large volume of cargo, which is almost four times more than rail and four hundred times higher than air transportation in total (Martin and Stopford, 2009). Containerization facilitates this method of transferring goods and attracts huge amounts of cargo to shipping. Containers are large standardized boxes, one of the biggest inventions in the history of maritime trade for transfer of goods, pioneered by American entrepreneur Malcom McLean in 1956 (Cudahy, 2006).

Containerization brings not only opportunities, but also restrictions to the maritime industry, mostly applicable to container terminals (Bandeira et al., 2009). Challenges come into consideration because containerization significantly changes the requirements for terminal facilities. Container terminals need to be built and used, along with berths and cranes that are powerful enough to handle container ships. Additionally, container terminals are required to invest in straddle carriers, tractors, trailers to shift containers from berthing facilities to the yard and yard to the gate, and vice versa. It is imperative to setup sufficient storage facilities to ease the process of temporary storage of containers to facilitate import, export and transhipment procedures. These are just a few examples of the minimum required facilities with proper capacity to move containers from one port to another.

\section{PROBLEM STATEMENT}

The increasing number of containers and the mounting dimensions of vessels are adding stress to seaports to increase the capacity of container terminals. Ports are bound to respond with new terminals and added infrastructure facilities. For example, according to the United Nations, more than 700 new container berths will be required in East Asian ports between 2007 to 2015 to accommodate anticipated growth in container trade (UN and Korea Maritime Institute, 2007). The ocean transport industry is growing at a faster rate than seaports can build facilities (Pallis and de Langen, 2010) because it takes many years from 2 to over 10 from decision to completion of changes in the infrastructure to increase capacity (Henesey, 2006). As many terminals are exceeding capacity limits, seaports need to deal with the following severe problems:

\subsection{Congestion}

Congestion brings delays for port users and increases the costs to many stakeholders; for example, shipping lines (shipping delays, missed feeders), terminals (yard congestion, re-handling), trucking companies and railways (longer waiting time) and shippers (longer lead time) (Mabs, 2009).

\subsection{Ineffective Supply Chains}

Due to both physical (capacity problem) and economic (cargo consolidation) constraints, big container ships are calling on a smaller number of ports (Henesey et al., 2009). For example, mega ships with a capacity of 18,154 TEU (twenty-foot equivalent unit) have a draught of $21 \mathrm{~m}$ (Ircha, 2001) which will result in capacity shortage in many ports (Grossmann, 2008). With this type of increasing ship-size, deepwater coastal ports could gain a share of the liner ports (Baird, 2002) because of the change from multi-port-calling to a huband-spoke system (Imai et al., 2006). If the major exporting ports of a trading nation send overseas containers via a hub port in another country, problems will occur: there will be a rise in Transit Time to transport the containers in the export destinations, which will increase the chances of spoiling fresh goods, and there will be an increase in Cargo Handling Costs due to multiple freight handling in each port during transhipment.

\subsection{Higher Prices}

Capacity shortage increases the costs (i.e. higher surcharge) for port users (i.e. shippers, truckers etc.) in a competitive open market. This amplifies the total usual transportation costs of port routes and other cheaper or less congested ports may become more noticeable (Dekker, 2005). For more explanation on the interrelationship of demand, supply, cost and price, see Rinnooy Kan (1983).

\section{LITERATURE REVIEW}

To date, as far as we are aware, not many studies are published that review the factors affecting seaport capacity and we found only two papers that attempt to review part of the literature (Maloni and Jackson, 2005a, Maloni and Jackson, 2005b). Maloni and Jackson (2005a) reviews capacity issues and organizes related literature and suggests a taxonomy based on the interrelated operational and strategic stakeholders of container flows. However, the review has one major limitation: it only focuses on the stakeholders 
(i.e., involved parties) influencing capacity, i.e., it does not aim to select the factors influencing port capacity directly or indirectly. Another paper, by Maloni and Jackson (2005b), comes closest to what is attempted in the present article. In their contribution, they review twenty-five capacity factors that are derived explicitly from academic and industry literature. However, they exclude some important factors, which affect rail, truck and dry port capacities, and finally system-wide performance of the overall seaport capacity issues.

\section{RESEARCH METHODOLOGY}

All types of methodologies have their limitations. Although this paper follows a systematic procedure for searching, this structured process ensures objectivity of the research process in content analysis.

\subsection{Reliability Test}

To increase the reliability of the conducted research a second coder checks databases and journals as well as the individual industry reports. The content analytic schemes (i.e., the criterion type-coding schemes) are tested for intercoder reliability based on the rule of percent agreement (i.e., conformity or harmony): the number of matches between the two separated coders divided by the number of potential agreements. The minimum standard for acceptability for many studies has been established as $90 \%$ and for exploratory studies as $80 \%$ (Krippendorff, 2004). For this study, intercoder reliability of $91 \%$ is achieved after revising integrated category definitions for couple of times.

\subsection{Content Validity Test}

Content validity is the determination of the content representativeness. A claim for high content validity is made on the basis that categories are extracted directly from the journal articles describing particular contexts, which are different from each other. Here articles and reports generated criterion mentions in texts, served as instant judges of the actuality of the concepts. Moreover, cited references are used as a secondary source to be more certain, but have not received any supplementary paper, which is a sign of validity of the research. Furthermore, in order to cover all capacity dimensions, papers are searched and referred until sufficient redundancy is achieved.

\section{FACTORS AFFECTING CAPACITY}

A container distribution network forms a series of connected capacity components determined by many stakeholders such as ports, rail lines, drayage operators, terminal operators, stevedoring companies and shipping lines. Delay at any of those points can affect overall capacity severely.

Each specific component is very important for the performance of the whole system and for that of the subsequent components. The productivity of each component depends not only on its own performance but also on the performance of other components. For instance, a slow crane performance can occur because of the unavailability of supportive transports, limited skill and lack of experience of the crane operators, weak working capability of the crane itself, poor delivery of containers to the crane or other factors not related to the crane. Some capacity components of a typical port are described in the following:

\subsection{Container Yard}

The container yard is used for the temporary storage of containers. If there is sufficient land available, it is possible to put every container on a separate chassis, which will allow faster and easier movement of containers among dissimilar terminal locations.

\subsection{Cranes}

In a ship, many cranes work simultaneously. However, the performance of the cranes and the number of cranes in use depends on the size of the ship, the number of containers to be loaded or unloaded, the skill of the crane operators, the availability of the supportive transports such as straddle carriers and automated guided vehicles, and the requirements to stop the cranes and the other factors.

\subsection{Labour}

Labour is not a specific component of the container terminal system if we view the port as a connected series of processes and sub-processes. However, it affects the performance of almost all of the processes rigorously from gate operations for truckers to berthing activities for shipping lines. 


\subsection{Gates}

Some ports are using a Vehicle Booking System (VBS) to spread container flows evenly throughout the day and thus use existing capacity more effectively. Seaports worldwide are adopting the VBS concept very quickly (Robinson, 2003).

\subsection{Inland Waterways}

Short Sea Shipping (SSS) provides an alternative and efficient option for transporting containers out of ports to other ports, which increases the existing capacity and reduces many of the capacity burdens.

There are many factors that affect capacity of each component of the terminal system. Factors which affect a particular component are usually different from the factors affecting other components in the system. For example, factors affecting the capacity of highway trucks are design speed, gate congestion, degree of automation at the gate, lane attributes, which are different from the factors affecting container yard capacity. An extensive review of the factors from academic and industry papers is listed in Figure 1. For a full list of the literature reviewed, interested readers are requested to contact the corresponding author.

\section{RESEARCH OPPORTUNITIES}

Port capacity expansion is not an equipment replacement problem, it is about adding more capacity to the current one, which makes the situation complicated. Capacity problems can appear at any of the connected components in the container distribution network for the seaport, from gates and yard operations to berthing facilities. The traditional way to solve the problem is to divide it into several separate components although all are operationally connected and service quality in one component will disrupt other components, which can be investigated through simulation (Hamzawi, 1992). For example, during the 1990's California improved its port's capability to handle bigger container ships without updating the transport infrastructure connecting the port to the hinterlands, which created bottlenecks (Auckland Regional Holdings, 2009). Therefore, it is important to adopt a 'whole of seaport' approach for capacity management using system modelling, which might be system dynamics, discrete-event simulation or agent-based simulation, which aim to explain system behaviour and structure. Thus, many research opportunities exist on the factors affecting capacity; these are reviewed briefly below.

\subsection{System Dynamics (SD) Simulation}

Capacity management is a dynamic management problem, where a dynamic means changing with time. As indicated in Figure 2, the number of required gate entry lane decisions is not made only once; rather it is regularly observed and fine-tuned depending on the prediction and realization of traffic volumes in every year, which necessitates nonstop managerial activities, adjustment and checking. Moreover, dynamic management problems are created and continue because of the complex relationships among the system variables, which are also applicable for seaport processes and components (Cetin and Cerit, 2010). The occurrence of these attributes turn seaports into perfect candidates for SD simulation. The application of SD includes business, banking, economics, manufacturing, transportation and many others.

\begin{tabular}{|c|c|c|c|c|c|c|}
\hline \multicolumn{7}{|c|}{$\begin{array}{l}\text { Gate Lanes Required For Port of Cleveland } \\
\text { (Number of Trucks Per Month) }\end{array}$} \\
\hline Description & $\begin{array}{r}\text { Mon } \\
2\end{array}$ & verage & & $\begin{array}{l}\text { Average } \\
\text { 2400) }\end{array}$ & & $\begin{array}{l}\text { otuture } \\
\text { otential } \\
(\mathbf{4 0 0 0 )}\end{array}$ \\
\hline Total Trucks Per Week & \multicolumn{2}{|c|}{280} & \multicolumn{2}{|c|}{561} & & 935 \\
\hline Total Trucks Per Day & \multicolumn{2}{|c|}{56} & \multicolumn{2}{|c|}{112} & \multicolumn{2}{|r|}{187} \\
\hline Trucks Per Hour & \multicolumn{2}{|c|}{4} & \multicolumn{2}{|c|}{8} & \multicolumn{2}{|r|}{14} \\
\hline $\begin{array}{c}\text { Gate Entry Lane } \\
\text { (Required During Peak Hours) }\end{array}$ & 1 & 2 & 2 & 3 & 4 & 5 \\
\hline
\end{tabular}

Figure 2. Gate Lanes Required

Source: Port of Cleveland (2010) 


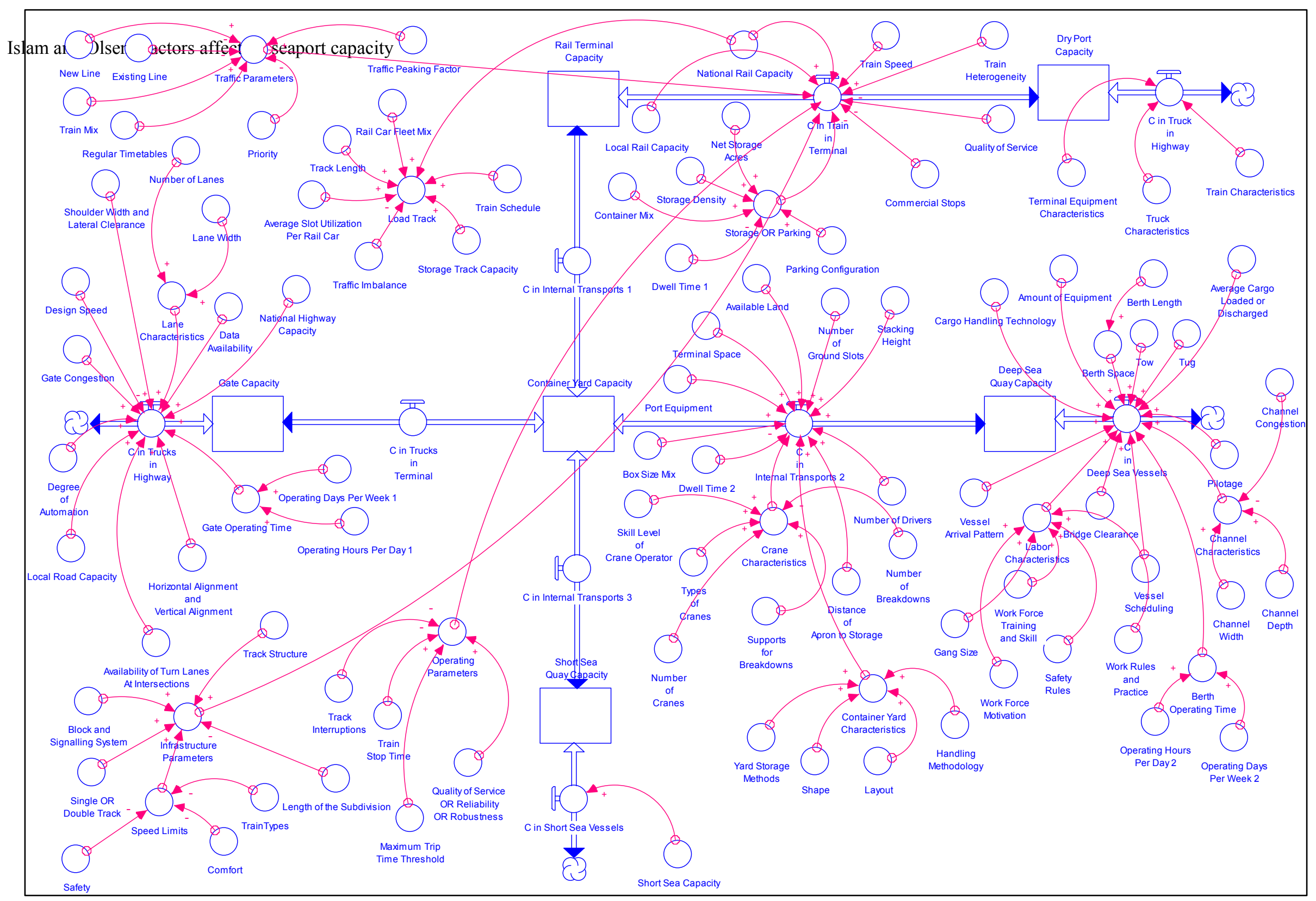

Figure 1. Stock and Flow View of Factors Affecting Seaport Capacity 
System dynamic models adopt a high level of aggregation and focus on the overall system behaviour ( $\mathrm{Ng}$ and Lam, 2010). It might be rational to make an accurate distinction and investigate the effects of nonstructural mechanisms for capacity improvement from an aggregate level using SD modelling, without tracking all details of a specific container terminal element, but capturing its impact on an explicit capacity component such as gate, yard, berth etc., to justify the appropriateness of policies and actions. It also permits what-if scenarios as a structural model for various policy makers.

\subsection{Discrete Event Simulation (DES)}

A container terminal is a decentralized, poorly structured, and complex problem domain (Gambardella et al., 1998). Modelling complex seaport operations requires a dynamic discrete event simulation model because internal resource conditions change with time (Nevins et al., 1998). Moreover, DES can quantify seaport operations to analyze port infrastructure utilization in detail (Hayuth et al., 1994). Ramani (1996) states the limitations of analytical queuing models for modelling port operations and Huang et al. (2008) affirms the limited applications of mathematical models, which optimize only one specific component rather than the whole container terminal. For example, queuing theory models assume certain situations (e.g., Markovian arrival processes), which are not realistic in practical port operations (Silberholz et al., 1991). But still the use of simulation in capacity management demands more research as stated "Little work has been done in container terminal capacity analysis using simulation" (Huang et al., 2008).

The purpose of Figure 3, which is a pyramid of research opportunities on factors affecting capacity, is to simplify and structure the interpretation and procedure of working with all connected capacity variables. The analysis starts with numerous structural and non-structural variables (i.e., conforming to "decreasing number of variables" as indicated in Figure 3) because SD (continuous simulation or deterministic approach) is a strategic tool, it is used at a much higher level for understanding (i.e., increasing level of abstraction as indicated in Figure 3) overall system behaviour. SEM (Structural Equation Modelling) can facilitate empirically testing the relationship among different latent variables of interest (e.g., degree of automation in gates; motivational level of terminal operators; quality of service, level of safety and comfort in rail transportation; skill level of crane operator, etc.) with several seaport performance variables (e.g.,truck turnaround time, crane productivity, congestion, etc.). DES is used for modelling queuing systems (e.g., seaports) where variability is important at a micro level and it is possible to incorporate individual features of a specific variable (i.e., decreasing number of variables as indicated in Figure 3).

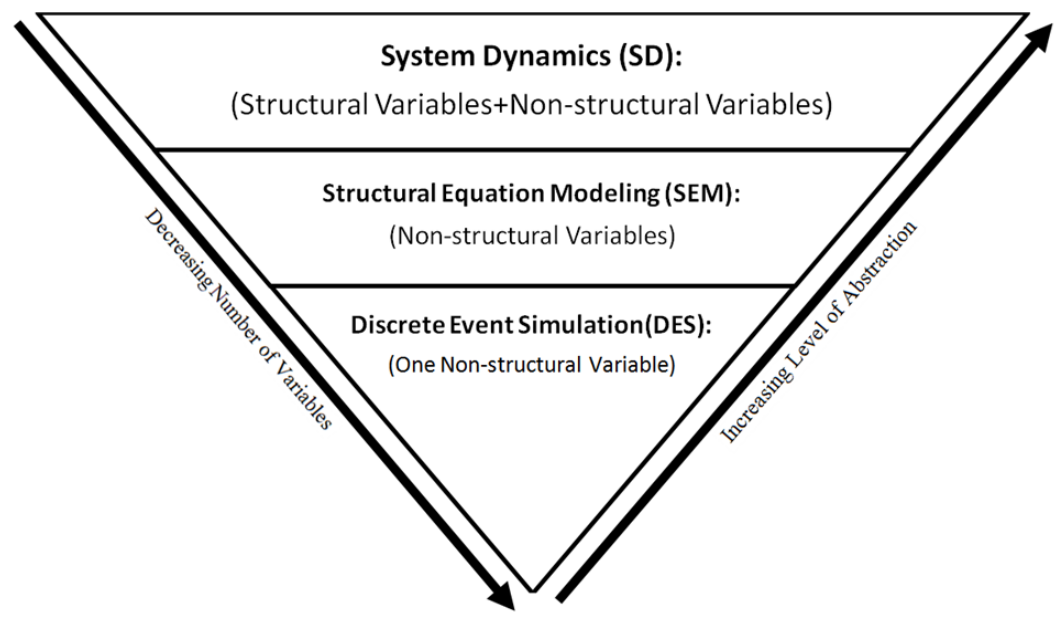

Figure 3. Research Opportunities Pyramid

\section{CONCLUSION}

This study offers a conceptualization (embedded in Figure 1) based on the extensive literature review of the academic and industry-related papers concerned with the factors influencing seaport capacity from a holistic point of view. Thus, the study takes a wider look at port capacity management. This study is significant as there is limited literature on this subject of factors affecting capacity and studies carried out so far on capacity improvement mechanisms are constrained principally by the lack of a complete and integrated perspective. This is the first such study conducted using completely integrated port capacity factors. Finally, the paper concludes by suggesting promising research tracks on factors affecting capacity. The aim is to arrive at a simulation tool that can be used for a variety of capacity improvement mechanisms, both from strategic (i.e., system simulation) and operational (i.e., discrete event simulation) points of view. 


\section{REFERENCES}

Auckland Regional Holdings (2009). Long-term optimisation of the New Zealand port sector: discussion paper.

Baird, A. J. (2002). The economics of container transhipment in Northern Europe. International Journal of Maritime Economics, 4, 249-280.

Bandeira, D. L., Becker, J. L. \& Borenstein, D. (2009). A DSS for integrated distribution of empty and full containers. Decision Support Systems, 47, 383-397.

Cetin, K. C. \& Cerit, A. G. (2010). Organizational effectiveness at seaports: A systems approach. Maritime Policy and Management, 37, 195-219.

Cudahy, B. J. (2006). The containership revolution: Malcom McLean's 1956 innovation goes global. TR News, 5-9.

Dekker, S. (2005). Port investment: towards an integrated planning of port capacity.

Gambardella, L. M., Rizzoli, A. E. \& Zaffalon, M. (1998). Simulation and planning of an intermodal container terminal. Simulation, 71, 107-116.

Grossmann, I. (2008). Perspectives for Hamburg as a port city in the context of a changing global environment. Geoforum, 39, 2062-2072.

Hamzawi, S. G. (1992). Lack of airport capacity: exploration of alternative solutions. Transportation Research Part A: Policy and Practice, 26, 47-58.

Hayuth, Y., Pollatschek, M. A. \& Roll, Y. (1994). Building a port simulator. Simulation, 63, 179-189.

Henesey, L., Davidsson, P. \& Persson, J. A. (2009). Evaluation of automated guided vehicle systems for container terminals using multi agent based simulation. In: NUNO, D., JAIME, S. \& O, S. (eds.) Multi-Agent-Based Simulation IX. Springer-Verlag.

Henesey, L. E. (2006). Multi-agent systems for container terminal management. PhD Doctoral Dissertation, Blekinge Institute of Technology.

Huang, S. Y., Hsu, J., Chen, C., YE, R. \& Nautiyal, S. (2008). Capacity analysis of container terminals using simulation techniques. International Journal of Computer Applications in Technology, 32, 246- 253.

Imal, A., Nishimura, E., Papadimitriou, S. \& Liu, M. (2006). The economic viability of container megaships. Transportation Research Part E: Logistics and Transportation Review, 42, 21-41.

Ircha, M. C. (2001). Serving tomorrow's mega-size containerships: the Canadian solution. International Journal of Maritime Economics, 3, 318-332.

Krippendorff, K. (2004). Content analysis: an introduction to its methodology, Sage.

Mabs (2009). Multi-agent-based simulation IX international workshop, MABS 2008, Estoril, Portugal, May 12-13, 2008 ; revised selected papers, Berlin : Springer, c2009.

Maloni, M. \& Jackson, E. C. (2005a). North American container port capacity: a literature review. Transportation Journal, 44, 16-36.

Maloni, M. \& Jackson, E. C. (2005b). North American container port capacity: an exploratory analysis. Transportation Journal, 44, 1-22.

Martin, S. \& Stopford, M. (2009). Maritime economics, London ; New York : Routledge, 2009.

Nevins, M. R., Macal, C. M. \& Joines, J. C. (1998). A discrete-event simulation model for seaport operations. Simulation, 70, 213-223.

Ng, T.-S. \& Lam, S.-W. (2010). Dynamic maritime systems inquiry: The DIVER approach. Systems Engineering.

Pallis, A. A. \& De Langen, P. W. (2010). Seaports and the structural implications of the economic crisis. Research in Transportation Economics, 27, 10-18.

Ramani, K. V. (1996). An interactive simulation model for the logistics planning of container operations in seaports. Simulation, 66, 291-300.

Rinnooy Kan, A. H. G. (1983). Capacity expansion — analysis of simple models with applications, by John Freidenfels, North Holland, 1981, 291 pp. Networks, 13, 303-303.

Robinson, B. (2003). Container terminal vehicle booking systems. Cargo Systems, 30, 16.

Silberholz, M. B., Golden, B. L. \& Baker, E. K. (1991). Using simulation to study the impact of work rules on productivity at marine container terminals. Computers and Operations Research, 18, 433-452.

UN \& Korea Maritime Institute. (2007). Regional shipping and port development [Online]. New York.

Available:http://www.unescap.org/ttdw/Publications/TIS_pubs/pub_2484/pub_2484_fulltext.pdf [Accessed 02 February 2011]. 